\title{
Cardiometabolic Risk Assessments by Body Mass Index $z$-Score or Waist-to-Height Ratio in a Multiethnic Sample of Sixth-Graders
}

\author{
Henry S. Kahn, ${ }^{1}$ Laure El ghormli, ${ }^{2}$ Russell Jago, ${ }^{3}$ Gary D. Foster, ${ }^{4}$ \\ Robert G. McMurray, ${ }^{5}$ John B. Buse, ${ }^{6}$ Diane D. Stadler, ${ }^{7}$ Roberto P. Treviño, ${ }^{8}$ \\ Tom Baranowski, ${ }^{9}$ and HEALTHY Study Group ${ }^{2}$ \\ ${ }^{1}$ Division of Diabetes Translation, Centers for Disease Control \& Prevention, CDC Mail Stop F-73, 4770 Buford Highway, \\ Atlanta, GA 30341, USA \\ ${ }^{2}$ The Biostatistics Center, George Washington University, Rockville, MD 20852, USA \\ ${ }^{3}$ School for Policy Studies, University of Bristol, Bristol BS8 1TZ, UK \\ ${ }^{4}$ Center for Obesity Research and Education, Temple University, Philadelphia, PA 19122, USA \\ ${ }^{5}$ Department of Exercise \& Sport Science, University of North Carolina, Chapel Hill, NC 27599, USA \\ ${ }^{6}$ Division of Endocrinology, Department of Medicine, University of North Carolina School of Medicine, Chapel Hill, NC 27599, USA \\ ${ }^{7}$ Division of Health Promotion \& Sports Medicine, Oregon Health \& Science University, Portland, OR 97239, USA \\ ${ }^{8}$ Social \& Health Research Center, San Antonio, TX 78210, USA \\ ${ }^{9}$ Children's Nutrition Research Center, Baylor College of Medicine, Houston, TX 77030, USA
}

Correspondence should be addressed to Henry S. Kahn; hkahn@cdc.gov

Received 2 February 2014; Accepted 14 May 2014; Published 14 July 2014

Academic Editor: Terry Huang

Copyright @ 2014 Henry S. Kahn et al. This is an open access article distributed under the Creative Commons Attribution License, which permits unrestricted use, distribution, and reproduction in any medium, provided the original work is properly cited.

Convention defines pediatric adiposity by the body mass index $z$-score (BMIz) referenced to normative growth charts. Waistto-height ratio (WHtR) does not depend on sex-and-age references. In the HEALTHY Study enrollment sample, we compared BMIz with WHtR for ability to identify adverse cardiometabolic risk. Among 5,482 sixth-grade students from 42 middle schools, we estimated explanatory variations $\left(R^{2}\right)$ and standardized beta coefficients of BMIz or WHtR for cardiometabolic risk factors: insulin resistance (HOMA-IR), lipids, blood pressures, and glucose. For each risk outcome variable, we prepared adjusted regression models for four subpopulations stratified by sex and high versus lower fatness. For HOMA-IR, $R^{2}$ attributed to BMIz or WHtR was $19 \%-28 \%$ among high-fatness and $8 \%-13 \%$ among lower-fatness students. $R^{2}$ for lipid variables was $4 \%-9 \%$ among high-fatness and 2\%-7\% among lower-fatness students. In the lower-fatness subpopulations, the standardized coefficients for total cholesterol/HDL cholesterol and triglycerides tended to be weaker for BMIz (0.13-0.20) than for WHtR (0.17-0.28). Among high-fatness students, BMIz and WHtR correlated with blood pressures for Hispanics and whites, but not black boys (systolic) or girls (systolic and diastolic). In 11-12 year olds, assessments by WHtR can provide cardiometabolic risk estimates similar to conventional BMIz without requiring reference to a normative growth chart.

\section{Introduction}

The conventional definitions of pediatric adiposity depend on a measured body mass index (BMI, $\left.\mathrm{kg} / \mathrm{m}^{2}\right)$ interpreted relative to a reference distribution (BMI normative growth charts) for sex and age [1-3]. Because it has body weight in its numerator, BMI reflects generalized (total-body) enlargement with a simplified correction (as height ${ }^{2}$ ) for skeletal size. Pediatric adiposity has been defined alternatively by abdominal size, most commonly a waist circumference, because increased truncal adipose tissue is correlated better than generalized adiposity with cardiometabolic dysfunction $[4,5]$. Since waist circumference is a regional measurement, it reflects specifically only abdominal or central enlargement. It 
includes no correction for skeletal size. Thus, waist circumference also requires interpretation relative to its own reference distribution for sex and age. Comparisons of risk assessments in youth have generally found little difference between BMI and waist circumference in the ability of these indicators to identify cardiometabolic risk $[6,7]$.

The waist-to-height ratio (WHtR) is an adiposity indicator with waist circumference in the numerator and a simplified correction (as height) for skeletal size. WHtR does not depend on sex- or age-specific reference criteria [810]. In a large sample of US sixth-graders, we examined the performance of BMI $z$-score (BMIz, referenced to CDC 2000 growth charts for the United States [11]) and WHtR for the purpose of cardiometabolic risk assessment.

\section{Methods}

2.1. Study Design and Participants. Participants came from the baseline enrollment (sixth-grade students in 2006) of the HEALTHY Study, a cluster-randomized, controlled, primary prevention trial designed to improve indicators of adiposity and glycemic dysregulation among US middle-school children $[12,13]$. Seven research centers recruited 42 middle schools with at least $50 \%$ of students eligible to participate in the federally subsidized National School Lunch Program or belonging to an ancestral minority group at increased risk of type 2 diabetes (Hispanic, non-Hispanic black, or Native American). A detailed protocol and background details about the HEALTHY Study are available for download at http://www.healthystudy.org/.

We restricted a priori our analytic sample to students with integer ages of 11 or 12 years who were able to participate in physical education and did not have known diabetes. From 5950 eligible enrollees, we excluded 13 students due to missing or invalid data for the adiposity indicators (height, weight, and waist circumference). Additional 239 students were excluded for lack of outcome cardiometabolic risk variables, and 216 were excluded for lack of information on pubarche (an adjustment variable associated with adrenarche, growth pattern, and insulin resistance) [14-16]. This left a final sample of 5482 participants with complete data.

Participant ancestry (Hispanic, non-Hispanic black, nonHispanic white, other) and sex were self-reported. The study was approved by each research center's Institutional Review Board, and informed consent from parents and assent from students were obtained prior to data collection.

2.2. Adiposity Indicators, Blood Pressure, and Reporting of Pubarche. From measured height and weight, we calculated the sex- and age-specific BMIz based on the Centers for Disease Control and Prevention 2000 growth charts [11, 17]. Waist circumference was measured to the nearest $0.1 \mathrm{~cm}$ on bare skin just above the iliac crest following procedures of the National Health and Nutrition Examination Survey [18], and the WHtR was calculated.

Blood pressure was recorded three times using an Omron automated blood pressure monitor (with appropriate-size cuff) after the participant sat quietly for 5 minutes. The mean of the second and third recordings was used in all analyses. Pubarche was identified dichotomously from the participants' response to a standardized question on the appearance of underarm and pubic hair [19].

2.3. Laboratory Methods. Fasting blood samples were processed onsite and shipped to the HEALTHY central blood laboratory (Northwest Lipid Research Laboratories, University of Washington) [12]. Insulin was measured by an immunoenzymometric assay using a Tosoh 1800 autoanalyzer; the interassay and intra-assay precision analysis consistently showed a coefficient of variation $(\mathrm{CV})<10 \%$. The assay had low cross-reactivity with human C-peptide $(0 \%)$ and proinsulin (2\%). Glucose analyses were performed on a Roche $\mathrm{P}$ module autoanalyzer using the hexokinase method. The homeostasis model assessment of insulin resistance (HOMA-IR) was calculated from glucose $(\mathrm{mg} / \mathrm{dL})$ and insulin $(\mu \mathrm{U} / \mathrm{mL})$ concentrations using the following formula [20]:

$$
\text { HOMA-IR }=\frac{(\text { glucose } * 0.05551) *(\text { insulin })}{22.5} .
$$

Measurements of total plasma cholesterol, cholesterol in the lipoprotein fractions, and triglycerides were performed enzymatically on the Roche Modular-P autoanalyzer using well-standardized methods. The interassay CVs were consistently $<1.5 \%$ for total cholesterol and triglycerides and $<2 \%$ for HDL cholesterol. We calculated the total-to-HDL cholesterol ratio (Tc/HDLc), a variable that strongly predicts cardiovascular disease in adults [21] and may be more strongly associated than LDL-cholesterol or HDL-cholesterol concentrations with pediatric adiposity $[22,23]$.

2.4. Statistical Analyses. In addition to stratification by sex, we chose a priori to stratify our analyses by "high fatness" or "lower fatness" because the ability of adiposity indicators to identify adipose tissue mass, ectopic fat, and cardiometabolic risk variables may be stronger among children in a higher fatness category [23-26]. As defined for this report, the high-fatness level included students who were above the sex-specific median value for both BMIz and WHtR; any student below the median for either adiposity indicator was designated lower fatness. For each fatness level, we prepared sex-specific, linear-regression models adjusted for ancestry ( 4 categories) and pubarche (yes/no) to estimate the associations of continuous adiposity indicators with the continuous cardiometabolic risk factors (outcomes). Since blood pressure varies with height in children [27, 28] our models for blood pressure outcomes included an additional adjustment for height which was entered as a continuous variable. For all variables except $\mathrm{BMI}$, we calculated descriptive statistics without using reference-based corrections for sex or age. For indicators or outcomes that departed markedly from a normal distribution (WHtR, HOMA-IR, Tc/HDLc, HDL cholesterol, triglycerides, and (only for lower-fatness students) diastolic blood pressure), we transformed the variable by $\log _{e}$ or inverse square root to approach normality prior to their use in regression models [29]. 
TABLE 1: Description of cross-sectional sample at grade $6(N=5,482)$.

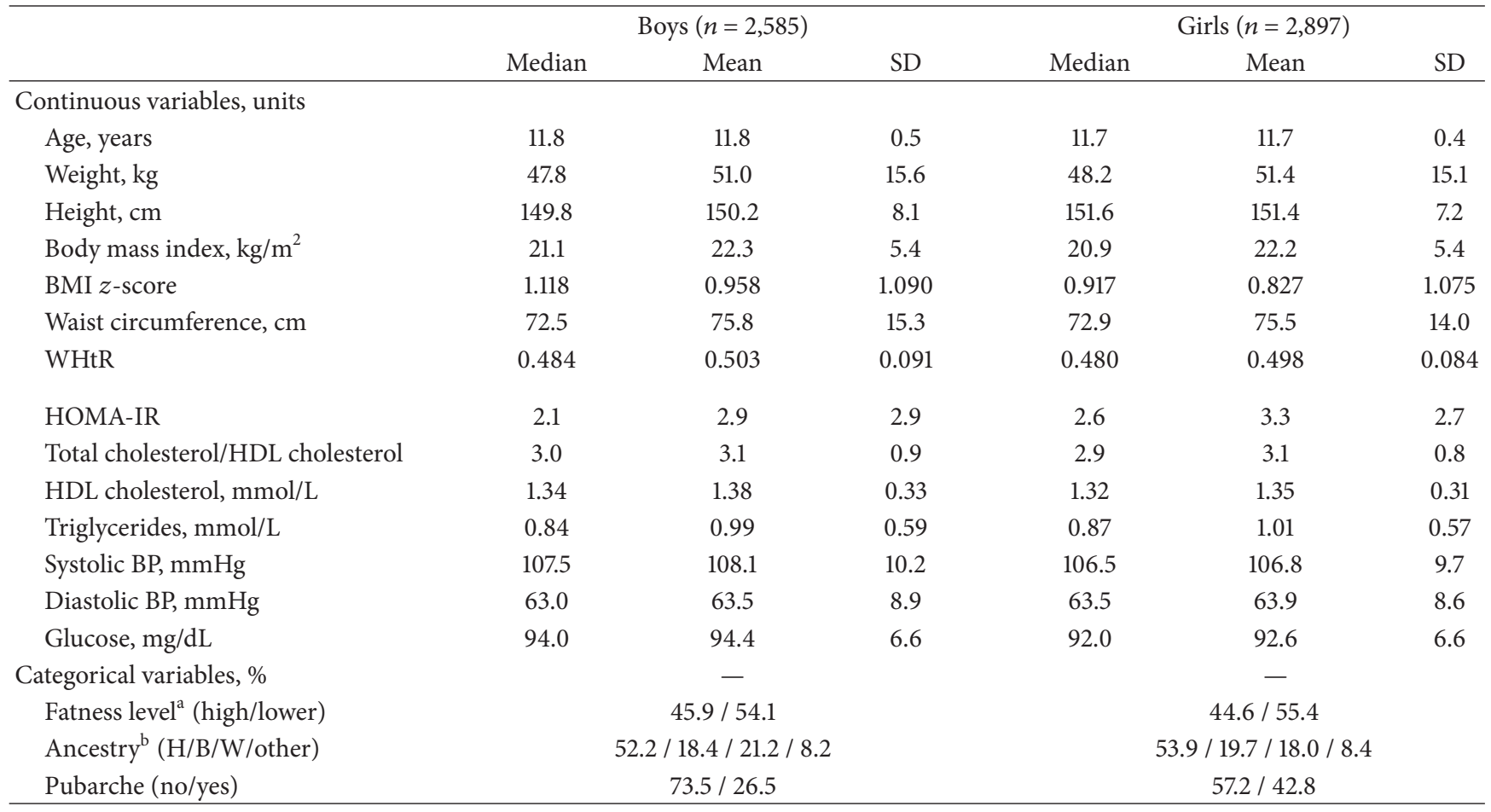

${ }^{a}$ High-fatness students identified by being above the sex-specific median value for both BMI $z$-score and WHtR; the remaining students were designated as lower-fatness.

${ }^{\mathrm{b}}$ H: Hispanic; B: non-Hispanic black; W: non-Hispanic white.

Our adjusted models estimated standardized beta coefficients (change in the outcome variable (in standard deviations) associated with change of one standard deviation in the adiposity indicator) for each cardiometabolic risk factor. PROC MIXED (SAS version 9.2; SAS Institute Inc., Cary, NC) was used to account for variability both within and between the school clusters. In these mixed models, the proportion of variation explained $\left(R^{2}\right)$ by each adiposity indicator was calculated as the full model $R^{2}$ minus $R^{2}$ for a model omitting the adiposity indicator. To compare linear slopes among ancestral groups, mixed-regression models estimated nonstandardized, beta-regression coefficients; interactions were tested between each adiposity indicator and the three ancestries represented prominently in our sample (Hispanic, black, and white). We report as noteworthy those ancestral contrasts where $P<0.01$.

\section{Results}

Characteristics of the analytic sample are presented by sex in Table 1. As expected for sixth-grade students [30], girls had greater height, insulin resistance, and triglycerides than boys. Following further stratification by fatness level, the distributions of adiposity indicators and ancestry are summarized in Table 2. Compared to the high-fatness groups in our sample, the lower-fatness groups had BMI and WHtR distributions that resembled more closely the general population of US youth in the same age range [31, 32].
Within the high-fatness subpopulations of either sex (Table 3), adiposity indicators explained $19 \%-28 \%$ of the variation in HOMA-IR, $4 \%-9 \%$ of the variation in circulating lipids (Tc/HDLc, HDL cholesterol, triglycerides), and 5\%9\% of the variation in diastolic blood pressure. Adiposity indicators explained $<3 \%$ of the variations in systolic blood pressure and fasting glucose. For each outcome variable in these high-fatness subpopulations, the effect sizes (standardized beta coefficients) associated with BMIz were similar to those associated with WHtR.

Within the lower-fatness subpopulations of either sex (Table 4 ), adiposity indicators explained $8 \%-13 \%$ of the variation in HOMA-IR and $2 \%-7 \%$ of the variation in circulating lipids. For Tc/HDLc and triglycerides, the standardized beta coefficients tended to be weaker for BMIz (0.13-0.20) than for WHtR (0.17-0.28). Adiposity indicators in these lowerfatness subpopulations explained $<1 \%$ of the variations in systolic blood pressure, diastolic blood pressure, and fasting glucose.

A comparison between the two levels of fatness (Table 3 versus Table 4) demonstrates that for either adiposity indicator the associations with HOMA-IR were stronger among the high-fatness students (beta coefficients $0.43-0.52$ ) than among the lower-fatness students (0.30-0.37). Similarly, both adiposity indicators were associated with diastolic blood pressure more strongly among high-fatness students (0.23$0.32 ; P<0.001$ for each of 4 beta coefficients) than among lower-fatness students $(0.03-0.05 ; P>0.05$ for each of four beta coefficients). For identification of lipid outcomes, 
TABLE 2: Distributions of adiposity indicators and ancestral groups. The analytic sample is divided into four mutually exclusive subpopulations by sex and fatness level.

\begin{tabular}{lcc}
\hline & Boys & Girls \\
\hline High fatness $^{\mathrm{a}}$ & & 1,291 \\
$n$ & 1,187 & $25.8(23.4,29.3)$ \\
Body mass index, median (p25, p75) & $25.9(23.6,29.2)$ & $1.78(1.41,2.14)$ \\
BMIz, median (p25, p75) & $1.91(1.60,2.20)$ & $0.562(0.524,0.614)$ \\
WHtR, median (p25, p75) & $0.574(0.533,0.625)$ & $58.6 / 18.4 / 15.4 / 7.5$ \\
Ancestry ${ }^{\mathrm{b}}$ (H/B/W/other), \% & $61.0 / 13.1 / 18.8 / 7.2$ & 1,606 \\
Lower fatness & & 1,398 \\
$n$ & $18.3(16.9,19.8)$ & $0.170(-0.443,0.657)$ \\
Body mass index, median (p25, p75) & $0.258(-0.361,0.754)$ & $0.436(0.411,0.460)$ \\
BMI $z$, median (p25, p75) & $0.432(0.408,0.457)$ & $50.0 / 20.8 / 20.1 / 9.1$ \\
WHtR, median (p25, p75) & $44.8 / 23.0 / 23.2 / 9.0$ & \\
Ancestry (H/B/W/other), \% & & \\
\hline
\end{tabular}

${ }^{a}$ High-fatness students identified by being above the sex-specific median value for both BMI $z$-score and WHtR; the remaining students were designated as lower-fatness.

${ }^{\mathrm{b}} \mathrm{H}$ : Hispanic; B: non-Hispanic black; W: non-Hispanic white.

p25 and p75 represent the 25th and 75th percentile values, respectively.

TABLE 3: Associations comparing standardized BMI $z$-score with standardized WHtR for estimating risk variable outcomes among highfatness students $(N=2,478)$.

\begin{tabular}{|c|c|c|c|c|c|c|c|c|}
\hline \multirow{3}{*}{ Risk outcome } & \multicolumn{4}{|c|}{ Boys $(n=1,187)$} & \multicolumn{4}{|c|}{ Girls $(n=1,291)$} \\
\hline & \multicolumn{2}{|c|}{ BMI $z$-score } & \multicolumn{2}{|c|}{$\mathrm{WHtR}^{-0.5}$} & \multicolumn{2}{|c|}{ BMI $z$-score } & \multicolumn{2}{|c|}{$\mathrm{WHtR}^{-0.5}$} \\
\hline & $\begin{array}{c}\text { Standardized beta } \\
(95 \% \mathrm{CI})\end{array}$ & $R^{2}$ & $\begin{array}{l}\text { Standardized beta } \\
(95 \% \mathrm{CI})\end{array}$ & $R^{2}$ & $\begin{array}{l}\text { Standardized beta } \\
(95 \% \mathrm{CI})\end{array}$ & $R^{2}$ & $\begin{array}{l}\text { Standardized beta } \\
(95 \% \mathrm{CI})\end{array}$ & $R^{2}$ \\
\hline Log HOMA-IR & $\begin{array}{c}0.52 \\
(0.48-0.57)\end{array}$ & 0.277 & $\begin{array}{c}0.48 \\
(0.43-0.53)\end{array}$ & 0.234 & $\begin{array}{c}0.47 \\
(0.42-0.52)\end{array}$ & 0.213 & $\begin{array}{c}0.43 \\
(0.38-0.48)\end{array}$ & 0.195 \\
\hline Log Tchol/HDLchol & $\begin{array}{c}0.29 \\
(0.23-0.34) \\
\end{array}$ & 0.083 & $\begin{array}{c}0.29 \\
(0.24-0.35) \\
\end{array}$ & 0.084 & $\begin{array}{c}0.23 \\
(0.18-0.29) \\
\end{array}$ & 0.057 & $\begin{array}{c}0.27 \\
(0.22-0.33) \\
\end{array}$ & 0.075 \\
\hline Log HDL cholesterol & $\begin{array}{c}-0.30 \\
(-0.35--0.24) \\
\end{array}$ & 0.092 & $\begin{array}{c}-0.28 \\
(-0.33--0.22)\end{array}$ & 0.077 & $\begin{array}{c}-0.27 \\
(-0.32--0.21)\end{array}$ & 0.075 & $\begin{array}{c}-0.28 \\
(-0.34--0.23)\end{array}$ & 0.079 \\
\hline Log triglycerides & $\begin{array}{c}0.24 \\
(0.19-0.29)\end{array}$ & 0.061 & $\begin{array}{c}0.24 \\
(0.18-0.29)\end{array}$ & 0.058 & $\begin{array}{c}0.19 \\
(0.14-0.24)\end{array}$ & 0.037 & $\begin{array}{c}0.22 \\
(0.17-0.27)\end{array}$ & 0.052 \\
\hline Systolic $\mathrm{BP}^{\mathrm{a}}, \mathrm{mmHg}$ & $\begin{array}{c}0.17 \\
(0.11-0.22)\end{array}$ & 0.028 & $\begin{array}{c}0.10 \\
(0.05-0.16)\end{array}$ & 0.011 & $\begin{array}{c}0.15 \\
(0.09-0.20)\end{array}$ & 0.021 & $\begin{array}{c}0.08^{*} \\
(0.03-0.13)\end{array}$ & 0.006 \\
\hline Diastolic $\mathrm{BP}^{\mathrm{a}}, \mathrm{mmHg}$ & $\begin{array}{c}0.32 \\
(0.26-0.37)\end{array}$ & 0.094 & $\begin{array}{c}0.29 \\
(0.23-0.34)\end{array}$ & 0.088 & $\begin{array}{c}0.28 \\
(0.22-0.33)\end{array}$ & 0.072 & $\begin{array}{c}0.23 \\
(0.18-0.28)\end{array}$ & 0.054 \\
\hline Glucose, mg/dL & $\begin{array}{c}0.04^{\dagger} \\
(-0.02-0.10)\end{array}$ & 0.001 & $\begin{array}{c}0.02^{\dagger} \\
(-0.04-0.07)\end{array}$ & 0.000 & $\begin{array}{c}0.08^{*} \\
(0.03-0.13)\end{array}$ & 0.005 & $\begin{array}{c}0.06^{*} \\
(0.01-0.12)\end{array}$ & 0.003 \\
\hline
\end{tabular}

${ }^{a}$ Models for blood pressures include an additional adjustment for height.

$R^{2}$ is the proportion of variation explained by the adiposity indicator.

All beta coefficients are $P<0.001$ with exception of ${ }^{*}(P<0.05)$ and ${ }^{\dagger}(P>0.05)$, not significant

Note that WHtR ${ }^{-0.5}$ is equivalent to $1 / \sqrt{\mathrm{WHtR}}$ or $1 / \mathrm{WHtR}^{0.5}$.

however, we found steeper beta coefficients only among high-fatness boys (compared to lower-fatness boys) whose adiposity was assessed by BMIz. For both sexes assessed by WHtR, the beta coefficients were similar across the fatness levels.

The associations between adiposity indicators and risk variables were not notably different between the Hispanics, non-Hispanic blacks, and non-Hispanic whites except when related to blood pressure outcomes. Although adiposity explained $5 \%-7 \%$ of variation in diastolic blood pressure in the complete sample of high-fatness girls (Table 3), this relationship was extremely weak for high-fatness girls who were black, as indicated by slope point estimates close to zero (Figure 1). However, for high-fatness girls who were Hispanic or white, BMIz and WHtR had significant associations $(P<0.05)$ with diastolic pressure. Among high-fatness boys, we found no ancestral contrasts related to diastolic pressure. 
TABLE 4: Associations comparing standardized BMI $z$-score with standardized WHtR for estimating risk variable outcomes among lowerfatness students $(N=3,004)$.

\begin{tabular}{|c|c|c|c|c|c|c|c|c|}
\hline \multirow{3}{*}{ Risk outcome } & \multicolumn{4}{|c|}{ Boys $(n=1,398)$} & \multicolumn{4}{|c|}{ Girls $(n=1,606)$} \\
\hline & \multicolumn{2}{|c|}{ BMI $z$-score } & \multicolumn{2}{|c|}{$\log \mathrm{WHtR}$} & \multicolumn{2}{|c|}{ BMI $z$-score } & \multicolumn{2}{|c|}{ Log WHtR } \\
\hline & $\begin{array}{l}\text { Standardized beta } \\
\qquad(95 \% \mathrm{CI})\end{array}$ & $R^{2}$ & $\begin{array}{l}\text { Standardized beta } \\
\qquad(95 \% \mathrm{CI})\end{array}$ & $R^{2}$ & $\begin{array}{l}\text { Standardized beta } \\
\qquad(95 \% \mathrm{CI})\end{array}$ & $R^{2}$ & $\begin{array}{l}\text { Standardized beta } \\
\qquad(95 \% \mathrm{CI})\end{array}$ & $R^{2}$ \\
\hline Log HOMA-IR & $\begin{array}{c}0.34 \\
(0.29-0.39) \\
\end{array}$ & 0.117 & $\begin{array}{c}0.30 \\
(0.25-0.35) \\
\end{array}$ & 0.083 & $\begin{array}{c}0.37 \\
(0.32-0.42) \\
\end{array}$ & 0.133 & $\begin{array}{c}0.31 \\
(0.27-0.36) \\
\end{array}$ & 0.098 \\
\hline Log Tchol/HDLchol & $\begin{array}{c}0.18 \\
(0.13-0.22) \\
\end{array}$ & 0.031 & $\begin{array}{c}0.26 \\
(0.21-0.32) \\
\end{array}$ & 0.063 & $\begin{array}{c}0.20 \\
(0.15-0.25) \\
\end{array}$ & 0.041 & $\begin{array}{c}0.28 \\
(0.23-0.33) \\
\end{array}$ & 0.074 \\
\hline Log HDL cholesterol & $\begin{array}{c}-0.19 \\
(-0.24--0.14) \\
\end{array}$ & 0.038 & $\begin{array}{c}-0.20 \\
(-0.26--0.15) \\
\end{array}$ & 0.037 & $\begin{array}{c}-0.22 \\
(-0.27--0.17) \\
\end{array}$ & 0.049 & $\begin{array}{c}-0.24 \\
(-0.29--0.19) \\
\end{array}$ & 0.053 \\
\hline Log triglycerides & $\begin{array}{c}0.14 \\
(0.09-0.19)\end{array}$ & 0.018 & $\begin{array}{c}0.22 \\
(0.16-0.27)\end{array}$ & 0.042 & $\begin{array}{c}0.13 \\
(0.08-0.18)\end{array}$ & 0.015 & $\begin{array}{c}0.17 \\
(0.12-0.22)\end{array}$ & 0.031 \\
\hline Systolic $\mathrm{BP}^{\mathrm{a}}, \mathrm{mmHg}$ & $\begin{array}{c}0.03^{\dagger} \\
(-0.02-0.08)\end{array}$ & 0.000 & $\begin{array}{c}-0.01^{\dagger} \\
(-0.06-0.04)\end{array}$ & $<0.001$ & $\begin{array}{c}0.04^{\dagger} \\
(-0.01-0.09)\end{array}$ & 0.001 & $\begin{array}{c}0.00^{\dagger} \\
(-0.05-0.05)\end{array}$ & $<0.001$ \\
\hline Log diastolic $\mathrm{BP}^{\mathrm{a}}$ & $\begin{array}{c}0.03^{\dagger} \\
(-0.03-0.08)\end{array}$ & 0.000 & $\begin{array}{c}0.05^{\dagger} \\
(-0.00-0.11)\end{array}$ & 0.002 & $\begin{array}{c}0.04^{\dagger} \\
(-0.01-0.09)\end{array}$ & 0.001 & $\begin{array}{c}0.05^{\dagger} \\
(-0.00-0.10)\end{array}$ & 0.002 \\
\hline Glucose, mg/dL & $\begin{array}{c}0.06^{*} \\
(0.01-0.11)\end{array}$ & 0.004 & $\begin{array}{c}0.05^{\dagger} \\
(-0.01-0.10)\end{array}$ & 0.002 & $\begin{array}{c}0.07^{*} \\
(0.02-0.12)\end{array}$ & 0.004 & $\begin{array}{c}0.04^{\dagger} \\
(-0.02-0.09)\end{array}$ & 0.002 \\
\hline
\end{tabular}

${ }^{a}$ Models for blood pressures include an additional adjustment for height.

$R^{2}$ is the proportion of variation explained by the adiposity indicator.

All beta coefficients are $P<0.001$ with exception of ${ }^{*}(P<0.05)$ and ${ }^{\dagger}(P>0.05)$, not significant.

Systolic blood pressure was not significantly associated with BMIz or WHtR for high-fatness blacks of either sex, but the association was present for high-fatness students who were Hispanic or white. An ancestral contrast (blacks compared to whites) related to systolic blood pressure was significant, however, only among the high-fatness girls assessed by BMIz (Figure 1; $P<0.01$ ).

\section{Discussion}

In this large sample of middle-school students at increased risk of obesity and type 2 diabetes, we found that adiposity indicators BMIz (with reference to CDC 2000 growth charts) and WHtR (without reference to sex and age) had similar utility for identifying adverse levels of cardiometabolic variables. Our findings are generally consistent with previous published reports, most of which were based on populations that had a wider age range or included less ancestral diversity. Earlier cross-sectional studies that compared continuous WHtR against BMI either without a normative growth reference [33-35] or with reference-based BMI $z$-scores/percentile ranks $[23,36]$ generally found that WHtR provided stronger associations with lipid outcomes, but BMI was superior for blood pressure outcomes. A recent report on sixth-grade students from Switzerland found that BMIz (referenced to CDC 2000 growth charts) and WHtR provided associations with blood pressures that were weak but nearly identical [37]. In studies of youth from the southern US, BMIz provided a slightly stronger association than WHtR with HOMA-IR [38] and fasting insulin [23], a relationship that was complicated by nonlinearity. Nationally representative, cross-sectional data from the US demonstrated that WHtR at ages 4-17 years was more strongly associated than BMIz with resting heart rate [36]. A longitudinal analysis from the same survey of adolescent and young-adult participants found that categorical WHtR predicted all-cause mortality before age 55 better than categorical BMIz (baseline ages 12-18 years) or BMI (ages 19-39) [39]. From the United Kingdom, a large study recently reported that WHtR and BMIz obtained at ages 7-9 years had similar associations with cross-sectional and prospective cardiometabolic risk factors in adolescence [40].

Given an approximately equal utility of BMIz and WHtR for pediatric health assessments, we should consider how these adiposity indicators might perform in different settings or in the future. BMIz values reported in the research literature depend on standardized protocols for measuring height and weight using calibrated, high-quality scales. In nonresearch settings, however, staff training and time pressures might not be so favorable to careful measurements [41]. The dependence of BMIz on normative growth references can be problematic because BMI-for-age reference values can yield discrepant inferences between populations, time periods [3], and ethnicities within a single country [42]. The International Obesity Task Force prepared a "worldwide" BMI growth reference based on large datasets from six countries [43], but subsequent reviews found that this international growth reference provided no advantage over national BMI growth references for the definition of excessive fat mass in youth [6] or prediction of subsequent cardiovascular risk in adulthood [44]. The World Health Organization (WHO) more recently developed a BMI-based growth reference [45], the utilization of which has been described as a cumbersome task in need of simplification [46]. Surveys from various clinical settings 

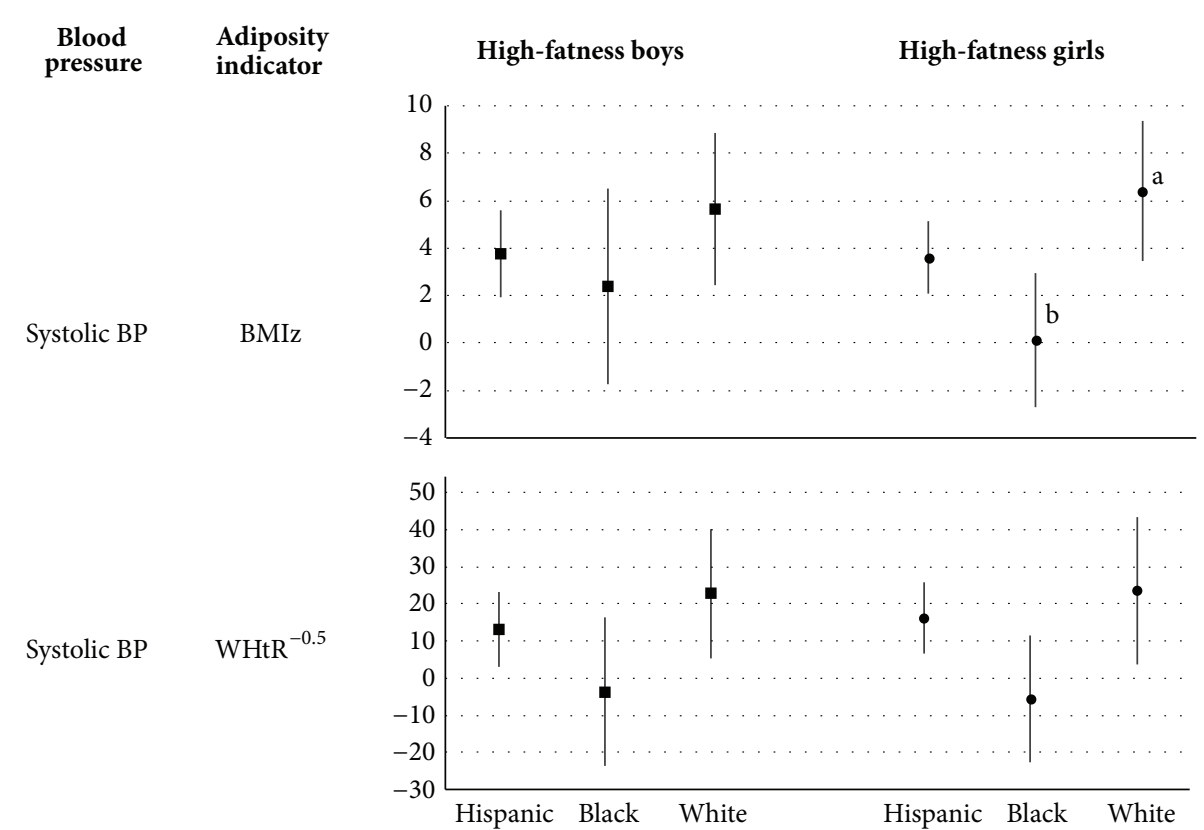

(a)

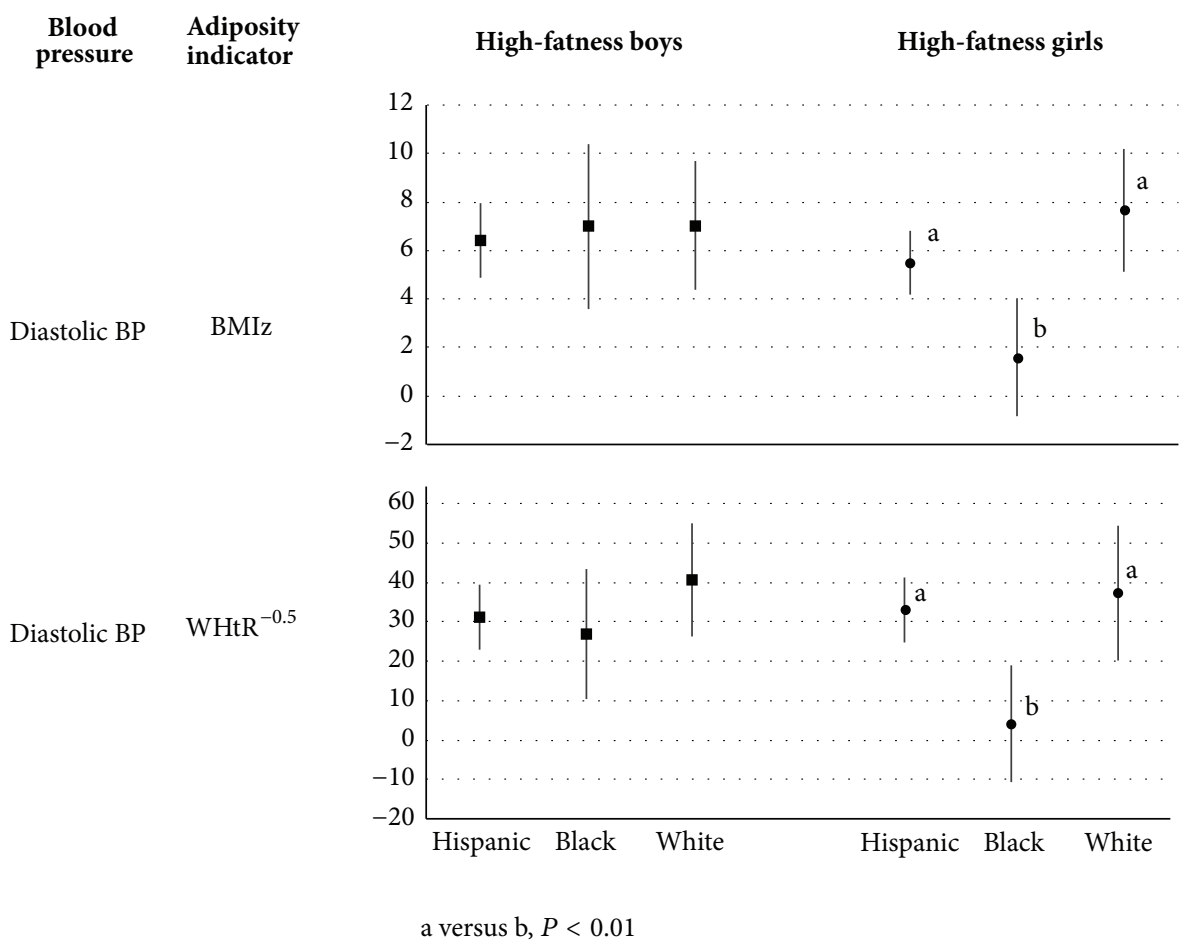

(b)

FIGURE 1: Within the high-fatness subpopulations, the point estimates (with 95\% confidence intervals) represent here the slopes of the associations between blood pressure and either BMIz or WHtR for 3 predominant ancestral groups (Hispanic, black, and white). Black participants exhibited no linear associations between systolic blood pressure and increasing adiposity (a). Diastolic blood pressure was related to increasing adiposity for black boys, but not black girls (b).

have found generally that the use of BMI-for-age reference values is suboptimal [47-50].

Advocates of the WHtR must address problems associated with the available protocols for measuring waist size.
While tape measures are inexpensive and generally need little calibration, protocols for circumference measurement are still unfamiliar to many pediatric practitioners or clinic assistants. Our study carefully measured the waist circumference 
just above the iliac crest, an anatomic location endorsed by prominent researchers in the United States $[18,51]$ and Canada [52]. The WHO, however, recommends measuring waist circumference at the approximate midpoint between the lower margin of the last palpable rib and the top of the iliac crest [53]. Waist circumferences have been taken also at the level of the umbilicus, the "minimal waist," and other sites $[54,55]$. In an anthropometric study of diabetic youth, the iliac-crest protocol and WHO protocol demonstrated comparable reproducibility, but these alternative protocols yielded notable differences in the absolute value of a waist circumference obtained from the same participants [56]. A study of overweight youth found that the WHO waistcircumference protocol had a stronger association than the iliac-crest protocol with cardiometabolic risk [57], and studies of adult waist circumference have likewise suggested an advantage for the WHO protocol [58-60]. It follows that the WHtR values calculated from the iliac-crest and WHO protocols should not be casually substituted for each other. It is possible that if our HEALTHY Study had adopted the WHO instead of the iliac-crest protocol for its baseline anthropometry, the re-calculated WHtR indicator might have demonstrated stronger associations with cardiometabolic risk variables than those we report in this paper. However, such WHO measurements are not available in the HEALTHY Study.

Standardization of a single waist-circumference protocol would probably advance the widespread adoption of the WHtR as a low-cost adiposity indicator $[55,61]$. As an alternative to the circumference, some pediatric investigators have described waist size in selected participants by measuring the external diameter sagittally (back-to-front) in the supine position [62-64]. Their reports suggest that standardization of a "sagittal abdominal diameter" protocol might further enhance studies that are cross-sectional or involve shortterm follow-up of central adiposity, but this anthropometric method needs to be tested in larger datasets that represent general youth populations.

The physiological importance of tissues accumulated in the waist may help to explain why WHtR was more closely associated than BMIz with variations in the levels of circulating lipid markers among our lower-fatness participants (Table 4). An increase in waist size primarily marks expanding amounts of adipose tissue, including notably the visceral depot which is most strongly associated with an adverse metabolic phenotype $[5,65]$. Variation in the waist circumference can explain more than $64 \%$ of the variance in the area [66] or volume [67] of visceral adipose tissue. An increase in BMI, by contrast, may substantially mark also the variations in gain of muscular weight or subcutaneous fat patterning that precede adulthood [1]. Along with the changes in fat mass, these variations in lean mass or superficial adipose tissue contribute to the BMI calculation while contributing relatively little to metabolic risk.

Although high-fatness Hispanic and white girls in our study demonstrated the expected associations between adiposity and blood pressure, we found among the high-fatness black girls (but not black boys) that neither BMIz nor WHtR had a significant association with blood pressure outcomes (Figure 1). In comparison to young Hispanics and whites, young blacks tend to have abdominal adipose tissue relatively less in the visceral depot and more in the abdominal subcutaneous regions [68]. Another study has also reported that black girls' waist circumference around the same age was unrelated to their diastolic blood pressure [69]. Since both the BMIz and WHtR indicators demonstrated similar patterns of nonassociation with black girls' blood pressure, it may be that this absence of a correlation with blood pressure is due to factors operating primarily outside the abdominal region. Perhaps black girls benefit from an increased capacity to expand their lower-body (gluteofemoral), subcutaneous, adipose-tissue stores in a manner that would increase their total body weight yet protect them from cardiometabolic risk [70-73]. If this protective characteristic of black girls extends into their later years, it could help explain why adult black women in the US experience no increased cardiometabolic risk [74] or mortality [75] until their BMI reaches approximately $33 \mathrm{~kg} / \mathrm{m}^{2}$.

\section{Conclusions}

If a well-standardized waist measurement comes into widespread use for clinical assessments of pediatric adiposity, patients and their families may improve their intuitive understanding of how excess adiposity contributes to adverse health risk. Pediatric health care providers, too, may find it more useful to recognize risk associated with a waist increment (corrected for height) than with a weight increment (corrected for height squared). Adoption of the WHtR could optimize both patient education and the tracking of risk [76]. Compared to BMI, the WHtR allows a simpler calculation without the necessity of squaring the child's height. Of interest to those concerned with child adiposity and cardiometabolic risk observed in different cultures or distinct time periods, the WHtR will facilitate comparisons based directly on anthropometric observations without using normative reference tables that may not be suitable to all populations [77-79].

\section{Abbreviations \\ BMIz: $\quad$ Body mass index $z$-score \\ BP: $\quad$ Blood pressure \\ $\mathrm{CV}$ : Coefficient of variation \\ CDC: $\quad$ Centers for Disease Control and Prevention \\ HDL: High-density lipoprotein \\ HOMA-IR: Homeostasis model assessment of insulin resistance \\ LDL: Low-density lipoprotein \\ Tc/HDLc: Total cholesterol/HDL cholesterol \\ WHtR: Waist-to-height ratio \\ WHO: World Health Organization.}

\section{Conflict of Interests}

The authors declare that there is no conflict of interests regarding the publication of this paper. 


\section{Authors' Contribution}

Henry S. Kahn, Tom Baranowski, and Russell Jago conceived the analysis and Laure El ghormli analyzed the data. Gary D. Foster, Robert G. McMurray, John B. Buse, Diane D. Stadler, and Roberto P. Treviño contributed to the data collection. Henry S. Kahn drafted the paper. All authors were involved in paper revision and had final approval of the submitted version.

\section{Acknowledgments}

This work is supported by Grants (U01-DK61230, U01DK61249, U01-DK61231, and U01-DK61223) from the National Institute of Diabetes and Digestive and Kidney Diseases (NIDDK) of the National Institutes of Health to the Studies to Treat or Prevent Pediatric Type 2 Diabetes (STOPP-T2D) collaborative group, with additional support from the American Diabetes Association. The funding bodies played no active role in study design; in the collection, analysis, and interpretation of data; in the writing of the paper; and in the decision to submit the paper for publication. John B. Buse received additional support from the National Center for Research Resources, Grant UL1RR025747, and the National Center for Advancing Translational Sciences, Grants UL1TR000083 and UL1TR001111. For interested researchers, the HEALTHY dataset is available through the NIDDK repository by following the standard request procedures outlined at https://www.niddkrepository.org/studies/healthy/. The authors thank the administrations, faculty, staff, and students and their families at the schools and school districts that participated in the HEALTHY study. The findings and conclusions in this report are those of the authors and do not necessarily represent the official position of the Centers for Disease Control and Prevention.

\section{References}

[1] M. Neovius, Y. Linné, B. Barkeling, and S. Rössner, "Discrepancies between classification systems of childhood obesity," Obesity Reviews, vol. 5, no. 2, pp. 105-114, 2004.

[2] S. E. Barlow, "Expert committee recommendations regarding the prevention, assessment, and treatment of child and adolescent overweight and obesity: summary report," Pediatrics, vol. 120, supplement 4, pp. S164-192, 2007.

[3] K. M. Flegal and C. L. Ogden, "Childhood obesity: are we all speaking the same language?" Advances in Nutrition, vol. 2, no. 2, pp. 159S-166S, 2011.

[4] C. Syme, M. Abrahamowicz, G. T. Leonard et al., "Intraabdominal adiposity and individual components of the metabolic syndrome in adolescence: sex differences and underlying mechanisms," Archives of Pediatrics and Adolescent Medicine, vol. 162, no. 5, pp. 453-461, 2008.

[5] A. G. Dulloo, J. Jacquet, G. Solinas, J.-P. Montani, and Y. Schutz, "Body composition phenotypes in pathways to obesity and the metabolic syndrome," International Journal of Obesity, vol. 34, no. 2, pp. S4-S17, 2010.

[6] J. J. Reilly, J. Kelly, and D. C. Wilson, "Accuracy of simple clinical and epidemiological definitions of childhood obesity: systematic review and evidence appraisal," Obesity Reviews, vol. 11, no. 9, pp. 645-655, 2010.

[7] J. J. Reilly, A. R. Dorosty, N. M. Ghomizadeh, A. Sherriff, J. C. Wells, and A. R. Ness, "Comparison of waist circumference percentiles versus body mass index percentiles for diagnosis of obesity in a large cohort of children," International Journal of Pediatric Obesity, vol. 5, no. 2, pp. 151-156, 2010.

[8] S. Nambiar, H. Truby, R. A. Abbott, and P. S. W. Davies, "Validating the waist-height ratio and developing centiles for use amongst children and adolescents," Acta Paediatrica, vol. 98, no. 1, pp. 148-152, 2009.

[9] L. M. Browning, S. D. Hsieh, and M. Ashwell, "A systematic review of waist-to-height ratio as a screening tool for the prediction of cardiovascular disease and diabetes: 0.5 could be a suitable global boundary value," Nutrition Research Reviews, vol. 23, no. 2, pp. 247-269, 2010.

[10] R. W. Taylor, S. M. Williams, A. M. Grant, B. J. Taylor, and A. Goulding, "Predictive ability of waist-to-height in relation to adiposity in children is not improved with age and sex-specific values," Obesity, vol. 19, no. 5, pp. 1062-1068, 2011.

[11] R. J. Kuczmarski, C. L. Ogden, S. S. Guo et al., "2000 CDC growth charts for the United States: methods and development," Vital and Health Statistics Series 11, no. 246, pp. 1-190, 2014, http://www.cdc.gov/growthcharts/2000growthchart-us.pdf.

[12] K. Hirst, T. Baranowski, L. DeBar et al., "HEALTHY study rationale, design and methods: moderating risk of type 2 diabetes in multi-ethnic middle school students," International Journal of Obesity, vol. 33, no. S4, pp. S4-S20, 2009.

[13] G. D. Foster, B. Linder, T. Baranowski et al., "A School-based intervention for diabetes risk reduction," The New England Journal of Medicine, vol. 363, no. 5, pp. 443-453, 2010.

[14] M. S. Boyne, M. Thame, C. Osmond et al., "Growth, body composition, and the onset of puberty: longitudinal observations in afro-Caribbean children," Journal of Clinical Endocrinology and Metabolism, vol. 95, no. 7, pp. 3194-3200, 2010.

[15] T. Oron, Y. Lebenthal, L. de Vries, M. Yackobovitch-Gavan, M. Phillip, and L. Lazar, "Interrelationship of extent of precocious adrenarche in appropriate for gestational age girls with clinical outcome," The Journal of Pediatrics, vol. 160, no. 2, pp. 308-313, 2012.

[16] A. N. Jeffery, B. S. Metcalf, J. Hosking et al., "Age before stage: insulin resistance rises before the onset of puberty," Diabetes Care, vol. 35, no. 3, pp. 536-541, 2012.

[17] Division of Nutrition Physical Activity and Obesity and National Center for Chronic Disease Prevention and Health Promotion, A SAS Program for the CDC Growth Charts, Centers for Disease Control and Prevention, Atlanta, Ga, USA, 2009, http://www.cdc.gov/nccdphp/dnpao/growthcharts/resources /sas.htm.

[18] National Center for Health Statistics, "Anthropometry Procedures Manual-National Health and Nutrition Examination Survey (NHANES)," 2011, http://www.cdc.gov/nchs/data/ nhanes/nhanes_11_12/Anthropometry_Procedures_Manual.pdf.

[19] A. C. Petersen, L. Crockett, M. Richards, and A. Boxer, "A selfreport measure of pubertal status: reliability, validity, and initial norms," Journal of Youth and Adolescence, vol. 17, no. 2, pp. 117133, 1988.

[20] B. Schwartz, D. R. Jacobs Jr., A. Moran, J. Steinberger, C. Hong, and A. R. Sinaiko, "Measurement of insulin sensitivity in children comparison between the euglycemic-hyperinsulinemic clamp and surrogate measures," Diabetes Care, vol. 31, no. 4, pp. 783-788, 2008. 
[21] Emerging Risk Factors Collaboration, "Lipid-related markers and cardiovascular disease prediction," The Journal of the American Medical Association, vol. 307, no. 23, pp. 2499-2506, 2012.

[22] S. Owens, B. Gutin, M. Ferguson, J. Allison, W. Karp, and N. Le, "Visceral adipose tissue and cardiovascular risk factors in obese children," Journal of Pediatrics, vol. 133, no. 1, pp. 41-45, 1998.

[23] D. S. Freedman, H. S. Kahn, Z. Mei et al., "Relation of body mass index and waist-to-height ratio to cardiovascular disease risk factors in children and adolescents: the Bogalusa Heart Study," The American Journal of Clinical Nutrition, vol. 86, no. 1, pp. 3340, 2007.

[24] D. S. Freedman, J. Wang, L. M. Maynard et al., "Relation of BMI to fat and fat-free mass among children and adolescents," International Journal of Obesity, vol. 29, no. 1, pp. 1-8, 2005.

[25] K. Kondaki, E. Grammatikaki, D. J. Pavón et al., "Comparison of several anthropometric indices with insulin resistance proxy measures among European adolescents: the Helena study," European Journal of Pediatrics, vol. 170, no. 6, pp. 731-739, 2011.

[26] B. Bennett, D. E. Larson-Meyer, E. Ravussin et al., "Impaired insulin sensitivity and elevated ectopic fat in healthy obese vs. nonobese prepubertal children," Obesity, vol. 20, no. 2, pp. 371375, 2012.

[27] H. S. Kahn, R. P. Bain, and B. Pullen-Smith, "Interpretation of children's blood pressure using a physiologic height correction," Journal of Chronic Diseases, vol. 39, no. 7, pp. 521-531, 1986.

[28] National High Blood Pressure Education Program Working Group on High Blood Pressure in Children and Adolescents, "The fourth report on the diagnosis, evaluation, and treatment of high blood pressure in children and adolescents," Pediatrics, vol. 114, no. 2, pp. 555-576, 2004.

[29] D. Scott, “Tukey's ladder of powers," Rice University, 2012, http://onlinestatbook.com/2/transformations/tukey.html.

[30] A. Moran, D. R. Jacobs Jr., J. Steinberger et al., "Changes in insulin resistance and cardiovascular risk during adolescence: establishment of differential risk in males and females," Circulation, vol. 117, no. 18, pp. 2361-2368, 2008.

[31] C. Li, E. S. Ford, A. H. Mokdad, and S. Cook, "Recent trends in waist circumference and waist-height ratio among US children and adolescents," Pediatrics, vol. 118, no. 5, pp. e1390-e1398, 2006.

[32] C. L. Ogden, M. D. Carroll, B. K. Kit, and K. M. Flegal, "Prevalence of obesity and trends in body mass index among US children and adolescents, 1999-2010," Journal of the American Medical Association, vol. 307, no. 5, pp. 483-490, 2012.

[33] S. C. Savva, M. Tornaritis, M. E. Savva et al., "Waist circumference and waist-to-height ratio are better predictors of cardiovascular disease risk factors in children than body mass index," International Journal of Obesity, vol. 24, no. 11, pp. 14531458, 2000.

[34] M. Hara, E. Saitou, F. Iwata, T. Okada, and K. Harada, "Waist-toheight ratio is the best predictor of cardiovascular disease risk factors in Japanese schoolchildren," Journal of Atherosclerosis and Thrombosis, vol. 9, no. 3, pp. 127-132, 2002.

[35] W. Yan, X. Wang, H. Yao et al., "Waist-to-height ratio and BMI predict different cardiovascular risk factors in Chinese children," Diabetes Care, vol. 29, no. 12, pp. 2760-2761, 2006.

[36] H. S. Kahn, G. Imperatore, and Y. J. Cheng, "A population-based comparison of BMI percentiles and waist-to-height ratio for identifying cardiovascular risk in youth," Journal of Pediatrics, vol. 146, no. 4, pp. 482-488, 2005.
[37] A. Chiolero, G. Paradis, K. Maximova, M. Burnier, and P. Bovet, "No use for waist-for-height ratio in addition to body mass index to identify children with elevated blood pressure," Blood Pressure, vol. 22, no. 1, pp. 17-20, 2013.

[38] R. G. McMurray, S. I. Bangdiwala, D. J. Catellier, and J. S. Harrell, "The relationship between insulin sensitivity and surrogates for adiposity in youth," International Journal of Child and Adolescent Health, vol. 3, no. 1, pp. 89-98, 2010.

[39] S. Saydah, K. M. Bullard, G. Imperatore, L. Geiss, and E. W. Gregg, "Cardiometabolic risk factors among US adolescents and young adults and risk of early mortality," Pediatrics, vol. 131, no. 3, pp. e679-e686, 2013.

[40] L. Graves, S. P. Garnett, C. T. Cowell et al., "Waist-to-height ratio and cardiometabolic risk factors in adolescence: findings from a prospective birth cohort," Pediatric Obesity, 2014.

[41] J. L. J. Greenwood, S. P. Narus, J. Leiser, and M. J. Egger, "Measuring body mass index according to protocol: how are height and weight obtained?" Journal for Healthcare Quality, vol. 33, no. 3, pp. 28-36, 2011.

[42] J. L. Miles-Chan, N. Joonas, S. Joganah et al., "BMI and cardiovascular function in children and adolescents of Mauritius Island," Journal of Nutritional Science, vol. 2, pp. 1-8, 2013.

[43] T. J. Cole, M. C. Bellizzi, K. M. Flegal, and W. H. Dietz, "Establishing a standard definition for child overweight and obesity worldwide: international survey," British Medical Journal, vol. 320, no. 7244, pp. 1240-1243, 2000.

[44] L. Li, A. P. de Moira, and C. Power, "Predicting cardiovascular disease risk factors in midadulthood from childhood body mass index: utility of different cutoffs for childhood body mass index," The American Journal of Clinical Nutrition, vol. 93, no. 6, pp. 1204-1211, 2011.

[45] M. de Onis, A. W. Onyango, E. Borghi, A. Siyam, C. Nishida, and J. Siekmann, "Development of a WHO growth reference for school-aged children and adolescents," Bulletin of the World Health Organization, vol. 85, no. 9, pp. 660-667, 2007.

[46] S. M. H. Nainar, "Simplified screening for overweight in children using the 2007 WHO Reference," Pediatric Obesity, vol. 7, no. 2, pp. el-e8, 2012.

[47] S. E. Barlow, S. R. Bobra, M. B. Elliott, R. C. Brownson, and D. Haire-Joshu, "Recognition of childhood overweight during health supervision visits: does BMI help pediatricians?" Obesity, vol. 15, no. 1, pp. 225-232, 2007.

[48] A. I. Patel, K. A. Madsen, J. H. Maselli, M. D. Cabana, R. S. Stafford, and A. L. Hersh, "Underdiagnosis of pediatric obesity during outpatient preventive care visits," Academic Pediatrics, vol. 10, no. 6, pp. 405-409, 2010.

[49] H. R. Wethington, B. Sherry, and B. Polhamus, "Physician practices related to use of BMI-for-age and counseling for childhood obesity prevention: a cross-sectional study, $B M C$ Family Practice, vol. 12, article 80, 2011.

[50] M. K. Andersen, B. Christensen, C. Obel, and J. Søndergaard, "Evaluation of general practitioners'assessment of overweight among children attending the five-year preventive child health examination: a cross-sectional survey," Scandinavian Journal of Primary Health Care, vol. 30, no. 3, pp. 176-182, 2012.

[51] National Institutes of Health, The Practical Guide to the Identification, Evaluation, and Treatment of Overweight and Obesity in Adults, US Department of Health and Human Services, Bethesda, Md, USA, 2000, http://www.nhlbi.nih.gov/guidelines/obesity/prctgd_c.pdf. 
[52] K. A. McGuire and R. Ross, "The revision of the measurement of waist circumference in the CPAFLA," 2008, http://www.csep.ca/English/view.asp?x=724\&id=84.

[53] World Health Organization, Waist Circumference and WaistHip Ratio: Report of a WHO Expert Consultation, Geneva, 8-11 December, 2008, WHO, Geneva, Switzerland, 2011, http://www.who.int/nutrition/publications/obesity/WHO_ report_waistcircumference_and_waisthip_ratio/en/.

[54] R. Ross, T. Berentzen, A. J. Bradshaw et al., "Does the relationship between waist circumference, morbidity and mortality depend on measurement protocol for waist circumference?" Obesity Reviews, vol. 9, no. 4, pp. 312-325, 2008.

[55] M. Ashwell and L. M. Browning, "The increasing importance of waist-to-height ratio to assess cardiometabolic risk: a plea for consistent terminology

," The Open Obesity Journal, vol. 3, pp. 70-77, 2011.

[56] D. J. Pettitt, J. W. Talton, A. D. Liese et al., "Comparison of two waist circumference measurement protocols: the SEARCH for diabetes in youth study," Pediatric Obesity, vol. 7, no. 6, pp. e81e85, 2012.

[57] S. T. Johnson, J. L. Kuk, K. A. Mackenzie, T. T. Huang, R. J. Rosychuk, and G. D. C. Ball, "Metabolic risk varies according to waist circumference measurement site in overweight boys and girls," The Journal of Pediatrics, vol. 156, no. 2, pp. 247.e1-252.el, 2010.

[58] A. Bosy-Westphal, C.-A. Booke, T. Blöcker et al., "Measurement site for waist circumference affects its accuracy as an index of visceral and abdominal subcutaneous fat in a caucasian population," Journal of Nutrition, vol. 140, no. 5, pp. 954-961, 2010.

[59] A. C. Vasques, L. E. Rosado, G. P. Rosado et al., "Different measurements of the sagittal abdominal diameter and waist perimeter in the prediction of HOMA-IR," Arquivos Brasileiros de Cardiologia, 2009, http://www.scielo.br/pdf/abc/v93n5/en_ aop00609.pdf.

[60] W.-Y. Ma, C.-Y. Yang, S.-R. Shih et al., "Measurement of waist circumference: midabdominal or iliac crest?" Diabetes Care, vol. 36, no. 6, pp. 1660-1666, 2013.

[61] S. K. Agarwal, A. Misra, P. Aggarwal et al., "Waist circumference measurement by site, posture, respiratory phase, and meal time: implications for methodology," Obesity, vol. 17, no. 5, pp. 10561061, 2009.

[62] S. Owens, M. Litaker, J. Allison, S. Riggs, M. Ferguson, and B. Gutin, "Prediction of visceral adipose tissue from simple anthropometric measurements in youths with obesity," Obesity Research, vol. 7, no. 1, pp. 16-22, 1999.

[63] K. Asayama, K. Dobashi, H. Hayashibe et al., "Threshold values of visceral fat measures and their anthropometric alternatives for metabolic derangement in Japanese obese boys," International Journal of Obesity and Related Metabolic Disorders, vol. 26, no. 2, pp. 208-213, 2002.

[64] K. C. Copeland, J. Higgins, L. El Ghormli et al., "Treatment effects on measures of body composition in the TODAY clinical trial," Diabetes Care, vol. 36, no. 6, pp. 1742-1748, 2013.

[65] S. E. Taksali, S. Caprio, J. Dziura et al., "High visceral and low abdominal subcutaneous fat stores in the obese adolescent: a determinant of an adverse metabolic phenotype," Diabetes, vol. 57, no. 2, pp. 367-371, 2008.

[66] P. Brambilla, G. Bedogni, L. A. Moreno et al., "Crossvalidation of anthropometry against magnetic resonance imaging for the assessment of visceral and subcutaneous adipose tissue in children," International Journal of Obesity, vol. 30, no. 1, pp. 2330, 2006.

[67] L. L. Benfield, K. R. Fox, D. M. Peters et al., "Magnetic resonance imaging of abdominal adiposity in a large cohort of British children," International Journal of Obesity, vol. 32, no. 1, pp. 9199, 2008.

[68] A. E. Staiano and P. T. Katzmarzyk, "Ethnic and sex differences in body fat and visceral and subcutaneous adiposity in children and adolescents.", International Journal of Obesity, vol. 36, no. 10, pp. 1261-1269, 2012.

[69] D. J. Tybor, A. H. Lichtenstein, G. E. Dallal, S. R. Daniels, and A. Must, "Independent effects of age-related changes in waist circumference and BMI z scores in predicting cardiovascular disease risk factors in a prospective cohort of adolescent females," The American Journal of Clinical Nutrition, vol. 93, no. 2, pp. 392-401, 2011.

[70] B. L. Heitmann and P. Frederiksen, “Thigh circumference and risk of heart disease and premature death: prospective cohort study," British Medical Journal, vol. 339, no. 7723, Article ID b3292, 2009.

[71] S. Virtue and A. Vidal-Puig, "Adipose tissue expandability, lipotoxicity and the Metabolic Syndrome-an allostatic perspective," Biochimica et Biophysica Acta-Molecular and Cell Biology of Lipids, vol. 1801, no. 3, pp. 338-349, 2010.

[72] K. N. Manolopoulos, F. Karpe, and K. N. Frayn, "Gluteofemoral body fat as a determinant of metabolic health," International Journal of Obesity, vol. 34, no. 6, pp. 949-959, 2010.

[73] K. Karastergiou, S. R. Smith, and A. S. Greenberg, "Sex differences in human adipose tissues-the biology of pear shape," Biology of Sex Differences, vol. 3, no. 1, article 13, 2014.

[74] P. T. Katzmarzyk, G. A. Bray, F. L. Greenway et al., "EthnicSpecific BMI and waist circumference thresholds," Obesity, vol. 19, no. 6, pp. 1272-1278, 2011.

[75] S. G. Lakoski, A. H. Le, P. Muntner et al., "Adiposity, inflammation, and risk for death in black and white men and women in the United States: The Reasons for Geographic and Racial Differences in Stroke (REGARDS) study," The Journal of Clinical Endocrinology and Metabolism, vol. 96, no. 6, pp. 1805-1814, 2011.

[76] M. Khoury, C. Manlhiot, S. Dobbin et al., "Role of waist measures in characterizing the lipid and blood pressure assessment of adolescents classified by body mass index," Archives of Pediatrics and Adolescent Medicine, vol. 166, no. 8, pp. 719-724, 2012.

[77] C. Maffeis, C. Banzato, and G. Talamini, "Waist-to-height ratio, a useful index to identify high metabolic risk in overweight children," The Journal of Pediatrics, vol. 152, no. 2, pp. 207.e2213.e2, 2008.

[78] A. Goulding, R. W. Taylor, A. M. Grant, W. R. Parnell, N. C. Wilson, and S. M. Williams, "Waist-to-height ratios in relation to BMI $\mathrm{z}$-scores in three ethnic groups from a representative sample of New Zealand children aged 5-14 years," International Journal of Obesity, vol. 34, no. 7, pp. 1188-1190, 2010.

[79] M. Ashwell, "Plea for simplicity: use of waist-to-height ratio as a primary screening tool to assess cardiometabolic risk," Clinical Obesity, vol. 2, no. 1-2, pp. 3-5, 2012. 


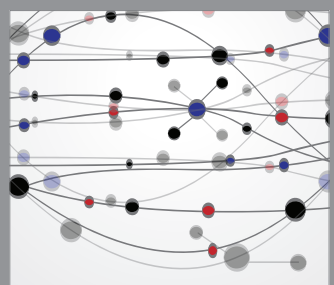

The Scientific World Journal
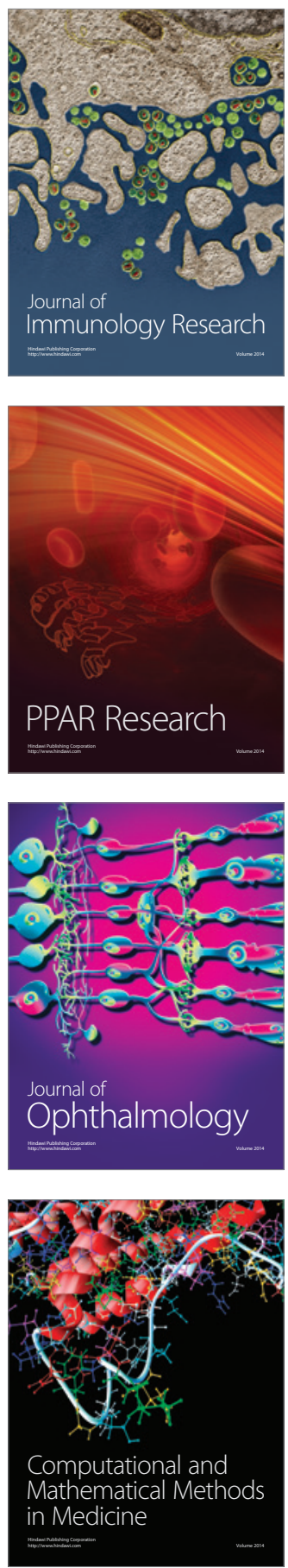

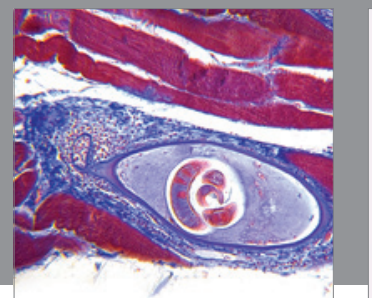

Gastroenterology

Research and Practice
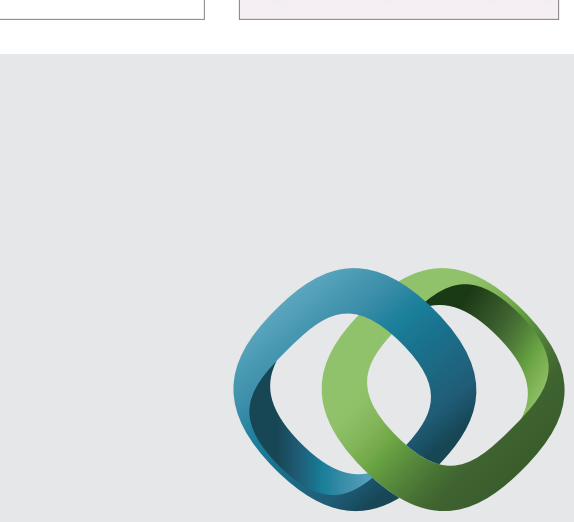

\section{Hindawi}

Submit your manuscripts at

http://www.hindawi.com
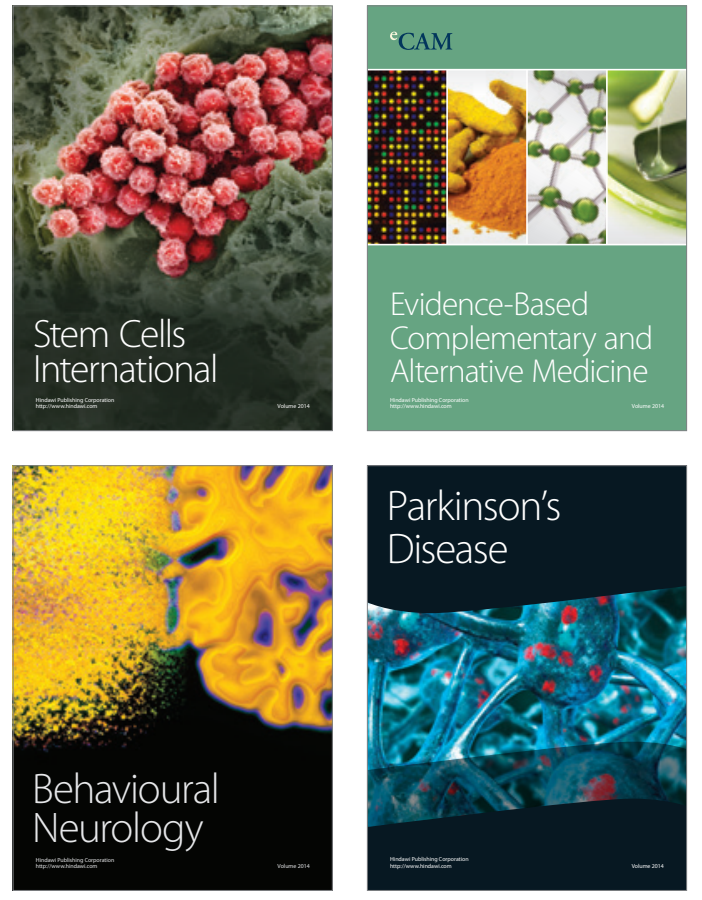
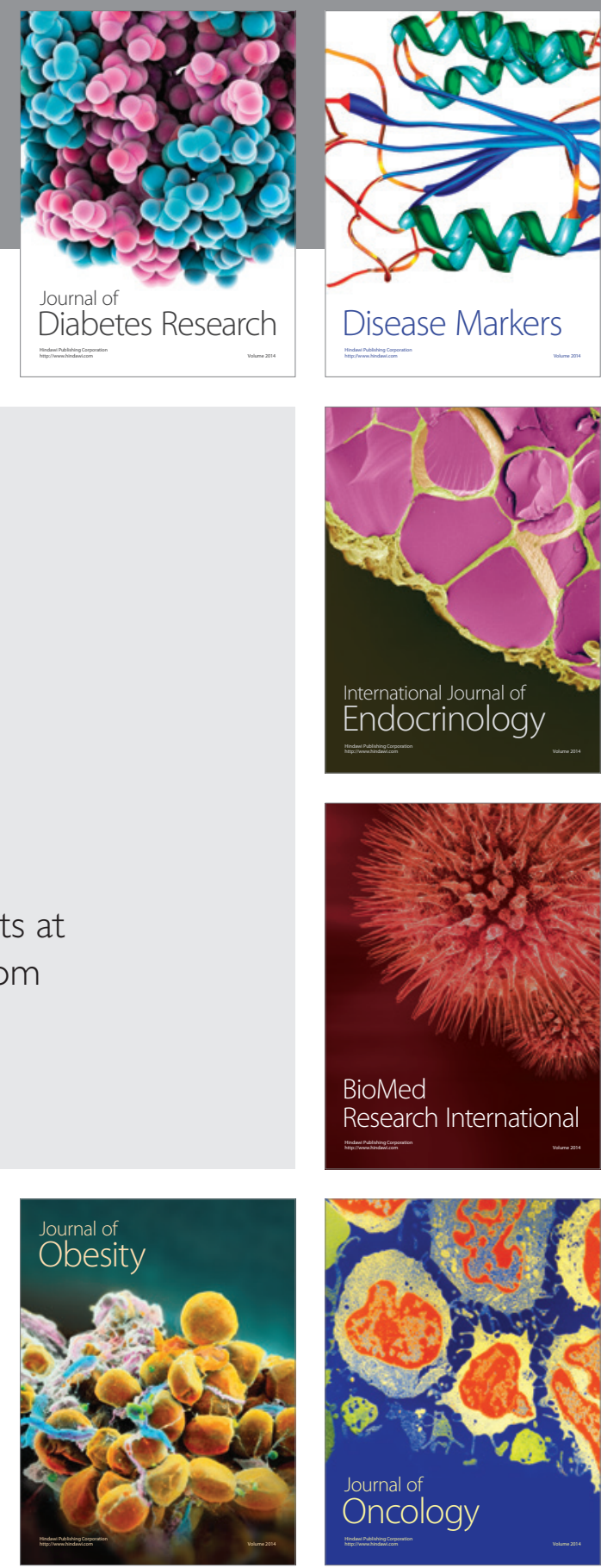

Disease Markers
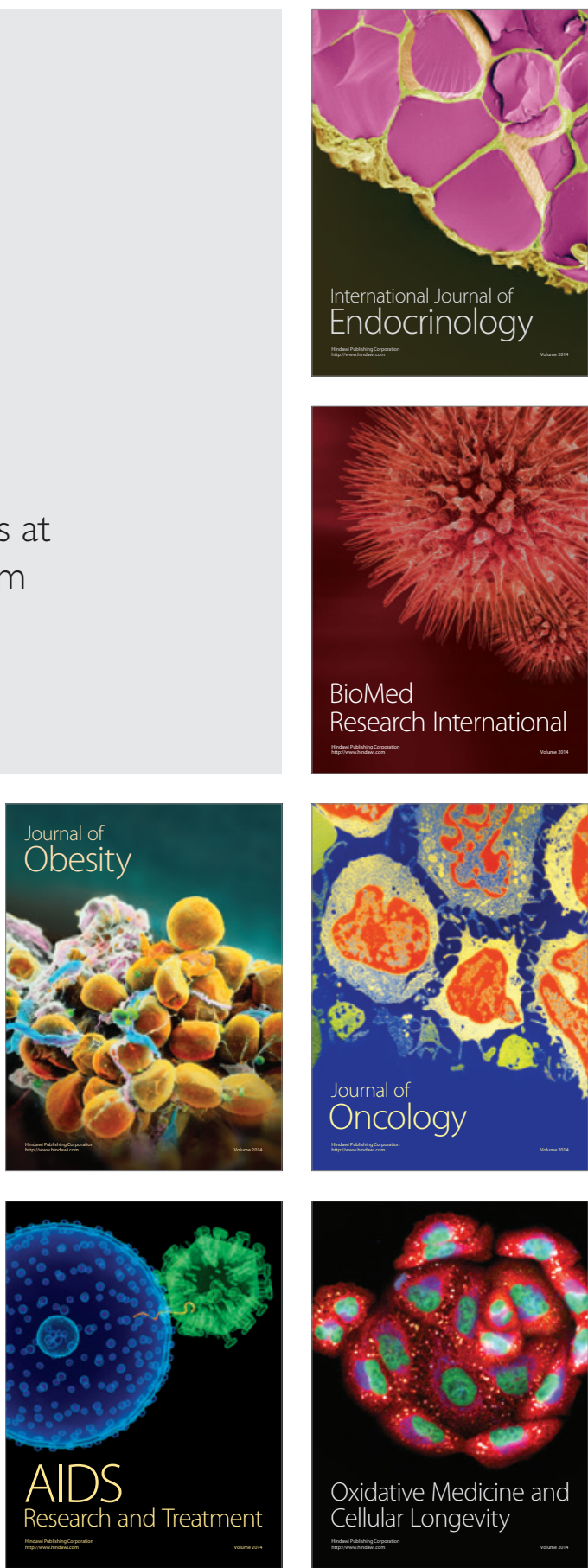